\title{
Compensatory growth in Microcystis aeruginosa after moderate high-temperature exposure
}

\author{
Wei HAN, Yuanshu JING, ${ }^{*}$ Ting LI \\ Jiangsu Key Laboratory of Agricultural Meteorology, College of Applied Meteorology, Nanjing University of Information Science \\ \&Technology, Nanjing, 210044, China
}

\begin{abstract}
This study aimed to investigate the mechanisms involved in Microcystis aeruginosa (M. aeruginosa) compensatory growth after moderate high-temperature stress. In the experiment, M. aeruginosa were cultured for 3,6 , and $12 \mathrm{~d}$ at $35^{\circ} \mathrm{C}$ before being transferred to normal conditions $\left(25^{\circ} \mathrm{C}\right)$, and then cultured for 30 days for recovery. The algae that were cultured constantly at $25^{\circ} \mathrm{C}$ were set as control. The results showed that the growth of $\mathrm{M}$. aeruginosa was inhibited significantly by the moderate high-temperature stress. During the recovery phase, the $\mathrm{M}$. aeruginosa cultured at $35^{\circ} \mathrm{C}$ for 3,6 , and 12 days exhibited under-compensation, over-compensation, and equal-compensation, respectively. To cope with moderate high-temperature stress, M. aeruginosa implement various mechanisms, including increasing antioxidant enzyme activities and chlorophyll a content; adjusting compatible solutes (soluble protein and sugar). The M. aeruginosa cultured at $35^{\circ} \mathrm{C}$ for 6 days has higher antioxidant enzyme activities, relatively low malondialdehyde content, and higher soluble sugar content during the recovery phase; therefore, M. aeruginosa cultured at $35^{\circ} \mathrm{C}$ for 6 days exhibited over-compensation growth. Grey correlation analysis revealed that the increase of chlorophyll a, soluble sugar, and superoxide dismutase activity play key roles in the compensatory growth of $\mathrm{M}$. aeruginosa.
\end{abstract}

Key words: Moderate high-temperature stress; Microcystis aeruginosa; over-compensatory growth; antioxidant enzymes.

Received: December 2014. Accepted: April 2015.

\section{INTRODUCTION}

Microcystis aeruginosa (M. aeruginosa) is one of the most harmful freshwater bloom-forming cyanobacteria, which are common in many eutrophic lakes around the world (Van Gremberghe et al., 2011; Sun et al., 2012; Ye et al., 2012; Barinova and Chekryzheva, 2014); cyanobacterial blooms may cause serious environmental and economic problems (Yu et al., 2010; Carvalho et al., 2011, 2013; Isaacs et al., 2014). Growth of M. aeruginosa is affected by many factors, such as temperature, light, and nutrient availability (Yang et al., 2012; Zhang et al., 2012; Lehman et al., 2013). Temperature has been considered to be a primary factor driving Microcystis blooms (Jacoby et al., 2000; Liu et al., 2011). Higher temperature strongly promotes the development of Microcystis blooms in summer (Joehnk et al., 2008; O’Neil et al., 2012). The optimal temperature for growth and photosynthesis of M. aeruginosa is $28^{\circ} \mathrm{C}$, which is higher than that of other phytoplankton species (Zehnder and Gorham, 1960; Robarts and Zohary, 1987). Moreover, sometimes, when the temperature exceeds $30^{\circ} \mathrm{C}$, the growth of $M$. aeruginos $a$ was not inhibited; a higher temperature of approximately $35^{\circ} \mathrm{C}$ often strongly promotes the development of cyanobacterial blooms in summer (Joehnk et al., 2008; Cai and Kong, 2013), which may be due to the compensatory growth of $M$. aeruginosa after high temperature stress.
Compensatory growth refers to the exceptionally rapid growth of individuals following a period of reduced growth resulting from suboptimal conditions (Yuan et al., 1998; Nikki et al., 2004). This phenomenon has been observed and intensively studied in a wide range of plants and animals (Belsky, 1986; Fang et al., 2014; Remen et al., 2014; Gong et al., 2015). Compensatory growth is considered a self defense system for organisms as an adaptation to variable environments (Bjorndal et al., 2003) (Turley et al., 2013). The degree of compensatory growth will vary with species (Mangel and Munch, 2005), stress level, and stress time (Flöder et al., 2010; Erbilgin et al., 2014). Understanding the mechanisms of compensatory growth that plants use to defend themselves, have attracted growing attention recently (Erbilgin et al., 2014; Robert et al., 2014). According to the degree of recovery that follows the period of restricted development, compensatory growth can be classified into three types, namely, over-compensation, equal-compensation, and under-compensation (Ali et al., 2003). Qin and Li (2010) demonstrated that $M$. aeruginosa cultured at $40^{\circ} \mathrm{C}$ for 5 days exhibited over-compensatory growth and that $M$. aeruginosa cultured at $40^{\circ} \mathrm{C}$ for 10 days exhibited complete compensatory growth. Although extreme temperatures of $40^{\circ} \mathrm{C}$ do not occur regularly, temperate and subtropical areas, where M. aeruginosa are found in abundance, continuously experience temperature increases to 
$35^{\circ} \mathrm{C}$ (Stocker et al., 2013), which leads to regular moderately high-temperature stress to $M$. aeruginosa. Thus, investigations on the compensatory growth under moderately high-temperature stress are especially necessary.

High temperature causes an array of biochemical changes in plants that affect plant growth and development (Wahid et al., 2007). Laxman et al. (2014) demonstrated that greater activity of superoxide dismutase (SOD) resulted in higher membrane stability under mild high-temperature stress. Wang et al. (2014) found that SOD and catalase (CAT) were all up-regulated under high temperature. Tikhomirova (1985) found that seed hardening at high temperature resulted in plants tolerant to overheating as well as higher levels of water-soluble proteins. Similarly, accumulation of soluble sugars under heat stress has been reported in sugarcane, which entails great implications for heat tolerance (Wahid and Close, 2007). The chlorophyll a (Chl-a) content in a certain algal cell is determined by temperature (Chen et al., 2011). For that reason, the changes in the biochemical characterization involved in compensatory growth should be studied.

Only a few studies have shown compensatory growth in M. aeruginosa under high temperature. Moreover, the mechanisms of this compensatory process have not been analyzed. How do M. aeruginosa adjust to high temperature? Those responses and adaptation are important for their survival and growth. Thus, it is useful to provide a better understanding of the biochemical mechanism of such compensatory growth. Therefore, a laboratory experiment was conducted to study the biochemical mechanism of the compensation process in M. aeruginosa under moderate high-temperature. Cell density, and some important biochemical parameters of M. aeruginosa, such as Chl-a, soluble sugar, soluble protein, SOD, CAT, peroxidase (POD), and malondialdehyde (MDA), were investigated.

\section{METHODS}

\section{Organisms and cultivation}

M. aeruginosa (FACHB 905) was obtained from the Institute of Hydrobiology, Chinese Academy of Sciences, which was isolated from Taihu Lake, PR China. The $M$. aeruginosa was batch cultured axenically in a liquid BG11 medium (Rippka et al., 1979) at $25^{\circ} \mathrm{C}$ and under coolwhite fluorescent lights (2000 lx), using a light-dark period of $12 \mathrm{~h}: 12 \mathrm{~h}$.

\section{Experimental design}

The cells in the mid-exponential growth phase were collected for the high temperature stress experiments. After each sample was sterilized, the algae were concentrated by centrifugation at $4000 \mathrm{r} / \mathrm{min}$ for $15 \mathrm{~min}$, and then the purified algae was inoculated into a liquid BG-11 medium in 250-mL flasks; the initial densities of algae in the experiments were all $2.52 \times 10^{6}$ cells $\mathrm{mL}^{-1}$.

The experiment is comprised of two phases: a stress phase and a recovery phase. The cells were cultured at a moderately high temperature of $35^{\circ} \mathrm{C}$, and $M$. aeruginosa cultured at $25^{\circ} \mathrm{C}$ was taken as the control. The stress phases lasting for 3 days, 6 days, and 12 days were referred to as the 3-d, 6-d, and 12-d groups, respectively; the recovery phase lasted for 30 days. At different days $(3,6$, and $12 \mathrm{~d})$, both in $35^{\circ} \mathrm{C}$ and $25^{\circ} \mathrm{C}$, algae were resuspended in a BG-11 medium in 500-mL flasks and cultured axenically at $25^{\circ} \mathrm{C}$ for 30 days. The cultures were shaken twice daily to maintain culture homogeneity; each treatment was replicated 3 times.

\section{Determination of the indices}

During the incubation period, the cell density of culture was monitored spectrophotometrically at $680 \mathrm{~nm}$ (OD680) every day. The regression equation between the density of algal cells $\left(\mathrm{y} \mathrm{mL}^{-1}\right)$ and OD680 (x) was established as:

$y=1.15 \times 10^{7} x+2.69 \times 10^{5}\left(R^{2}=0.99\right)$

The measurements were performed at the same period of the day to minimize the possible cell cycling effect. The Chl-a concentration was determined according to the method described by Huang et al. (1999). During the incubation period, the Chl-a concentration was determined every 3 days. A 5-mL aliquot of the sample solution was taken from each replicate bottle and gently filtered through a $0.7-\mu \mathrm{m}$ polycarbonate membrane for pigment determination. The Chl-a was extracted in $90 \%$ acetone solution for $24 \mathrm{~h}$ at $4^{\circ} \mathrm{C}$, and the concentration was determined via colorimetry. The activities of SOD, CAT, POD, and MDA were measured every 3 days during the culture period. The SOD activity was determined using a modified procedure of pyrogallol autooxidation ( $\mathrm{Gu}$ et al., 2006). One unit of SOD activity was defined as the amount of enzyme required to inhibit the autooxidation of pyrogallol to $50 \%$. The activity of CAT activity was assayed with a spectrophotometrical method according to the method of Rao et al. (1996). One unit of CAT was defined as the decrease of absorbance at $240 \mathrm{~nm}$ up to 0.1 in $1 \mathrm{~min}$. The POD activity was measured using the method of Chance and Maehly (1955) with guaiacol as an electron donor, and the absorbance of the supernatant was determined at $470 \mathrm{~nm}$. One enzyme unit was defined as the amount of enzyme causing an absorbance change of 0.001 per min under standard conditions. Lipid peroxidation is measured as the amount of MDA. The MDA content was determined using the thiobarbituric acid reaction, as described by Heath and Packer (1968). The soluble protein content was determined via protein-dye binding with 
Coomassie brilliant blue (Bradford, 1976), using bovine serum albumin as a protein standard. The content of soluble sugar was determined using the phenol-sulfuric acid method (Kochert, 1978).

\section{Statistical analyses}

Data of the five treatments were statistically evaluated using a one-way analysis of variance. The means were compared using Duncan's new multiple range test at the $5 \%$ level.

To evaluate quantitatively the compensation effect of $M$. aeruginosa after the moderate high-temperature stress, we calculated a compensation index (CI), using the following equation (Belsky, 1986):

$\mathrm{CI}=G / C$

Where $G$ is the cell density of the control, and $C$ is the cell density of the treatments after moderate high-temperature stress. $G / C>1$ denotes over-compensation, $G / C=1$ denotes equal-compensation, and $G / C<1$ denotes undercompensation. Grey correlation analysis was conducted to evaluate the impact of antioxidant enzyme activities, chlorophyll a content, soluble protein and sugar, and MDA on the $M$. aeruginosa density during the recovery phase (Deng, 1989).

The original impact factors and the target factor were represented as $\left\{X_{i(k)}\right\}$ and $\left\{X_{0(k)}\right\}$, respectively.

$$
\begin{aligned}
& \left\{X_{0(k)}\right\}=\left\{X_{0(1)}, X_{0(1)}, \ldots, X_{0(n)}\right\} k=1,2, \ldots, n \\
& \left\{X_{i(k)}\right\}=\left\{X_{i(1)}, X_{i(1)}, \ldots, X_{i(n)}\right\} k=1,2, \ldots, n ; i=1,2, \ldots, m
\end{aligned}
$$

where $m$ is the number of impact factors, and $n$ is the total number of observation data.

Grey data processing must be transformed to be dimensionless before grey correlation coefficients can be calculated. Each series is normalized to have mean equal zero and standard deviation equal one (Tang and Feng, 2006).

The correlation coefficient $\xi_{\mathrm{i}}(k)$ between the original impact factors and the target factor could be calculated as follows:

$\xi_{i}(k)=\frac{\min _{i} \min _{k}\left|x_{0}(k)-x_{i}(k)\right|+\rho \max _{i} \max _{k}\left|x_{0}(k)-x_{i}(k)\right|}{\left|x_{0}(k)-x_{i}(k)\right|+\rho \max _{i} \max _{k}\left|x_{0}(k)-x_{i}(k)\right|}(k=1,2, \ldots, n)$

where $\min _{i} \min _{k}\left|x_{0}(k)-x_{i}(k)\right|$ is the minimum absolute distance among all impact factors, and max max $\left|x_{0}(k)-x_{i}(k)\right|$ is the maximum absolute distance. $\rho$ is taken as 0.5 (Deng, 1989).

The grey correlation grade $r_{i(k)}$ is an average of the grey correlation coefficients that is defined as follows (Deng, 1989): $r_{i k)}=\frac{1}{n} \sum_{k=1}^{n} \xi_{i}(k)$

\section{RESULTS}

\section{Growth performance of $M$. aeruginosa}

According to Fig. 1, during the stress phase the growth of $M$. aeruginosa was significantly inhibited under moderately high temperature in a time-dependent manner. The difference between the two temperatures increased with time: after 12 days of culture, the cell density at $35^{\circ} \mathrm{C}$ decreased to $85.51 \%$ that of the control. During the entire recovery phase, for the mean cell density, the order is as follows: 6-d group $>$ control group $>12$-d group $>3-d$ group. Nevertheless, after 27 days of culture, the differences of the cell density among the different treatments narrowed, and the four groups tended to be the same. This result suggests that after the moderate high-temperature stress, the growth of $M$. aeruginosa also returned to the normal level.

The mean compensation indices for $M$. aeruginosa cell density are displayed in Fig. 2. The mean compensation indices varied from 0.72 to 1.06 . For the mean compensation indices, the order is as follows: 6-d group $>$ 12-d group $>3$-d group. There are significant differences among the 3-d group, the 6-d group, and the control. However, no significant difference was observed between the 12-d group and the control. According to the compensatory growth types, over-compensation was observed in the 6-d group, under-compensation was observed in the 3-d group, and equal-compensation was observed in the

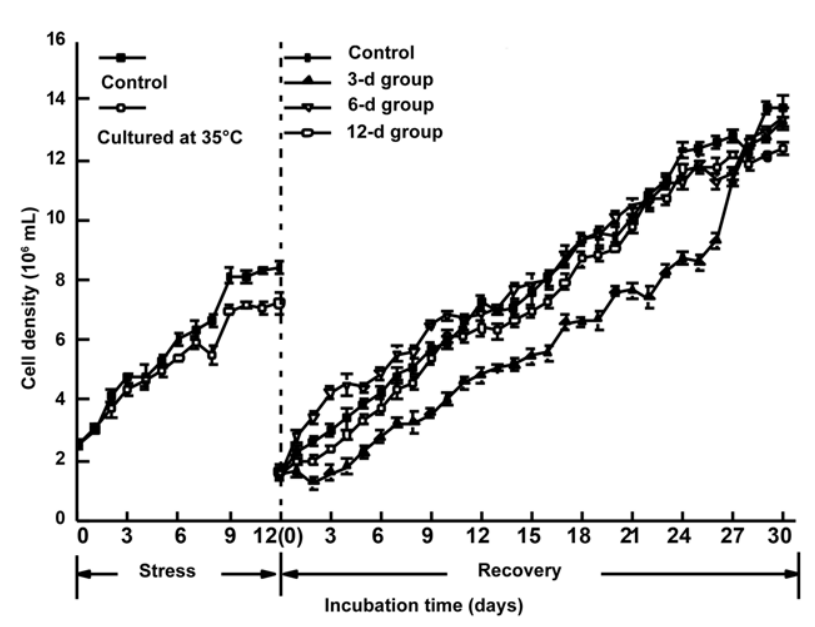

Fig. 1. Growth curves of $M$. aeruginosa during the stress phase and the recovery phase. $M$. aeruginosa cultured at $25^{\circ} \mathrm{C}$ is referred to as the control. M. aeruginosa cultured at $35^{\circ} \mathrm{C}$ for 3 , 6, and 12 days are referred to as the 3-d, 6-d, and 12-d groups, respectively. Error bars represent the standard deviations, $n=3$. 
12-d group. These results indicate that the M. aeruginosa growth of the 6-d group was the best.

\section{Content of Chl-a, soluble protein, and soluble sugar of M. aeruginosa}

As presented in Tab. 1, during the stress phase, the Chl-a concentration of $M$. aeruginosa cultured at $35^{\circ} \mathrm{C}$ was significantly lower than that at $25^{\circ} \mathrm{C}$, especially at day 3 . In the recovery phase, for the mean Chl-a concentration during the entire recovery phase, the order is as follows: 6-d group > 12-d group > 3-d group = control. During the stress phase, the soluble protein content of $M$. aeruginosa cultured at $35^{\circ} \mathrm{C}$ initially increased, peaked at day 6 , and then decreased gradually; while during the recovery phase, the soluble protein content of the $3-\mathrm{d}$ group was the highest. For the soluble sugar, during the stress phase, the soluble sugar content of $M$. aeruginosa cultured at $35^{\circ} \mathrm{C}$ was always lower than that of the control. During the recovery phase, the mean soluble sugar content of the 6-d group was the highest.

\section{Enzymatic antioxidants activities of $M$. aeruginosa}

As shown in Fig. 3a, during the stress phase, the SOD activity was significantly enhanced by moderately high temperature. The SOD activity increased with stress time. The SOD activity reached a maximum value of $0.176 \mathrm{U}$ mg pro $^{-1}$ when algal cells were cultured at $35^{\circ} \mathrm{C}$ for 12 days. During the recovery phase, the SOD activities in the 3-d, 6-d and 12-d groups were remarkably decreased dur-

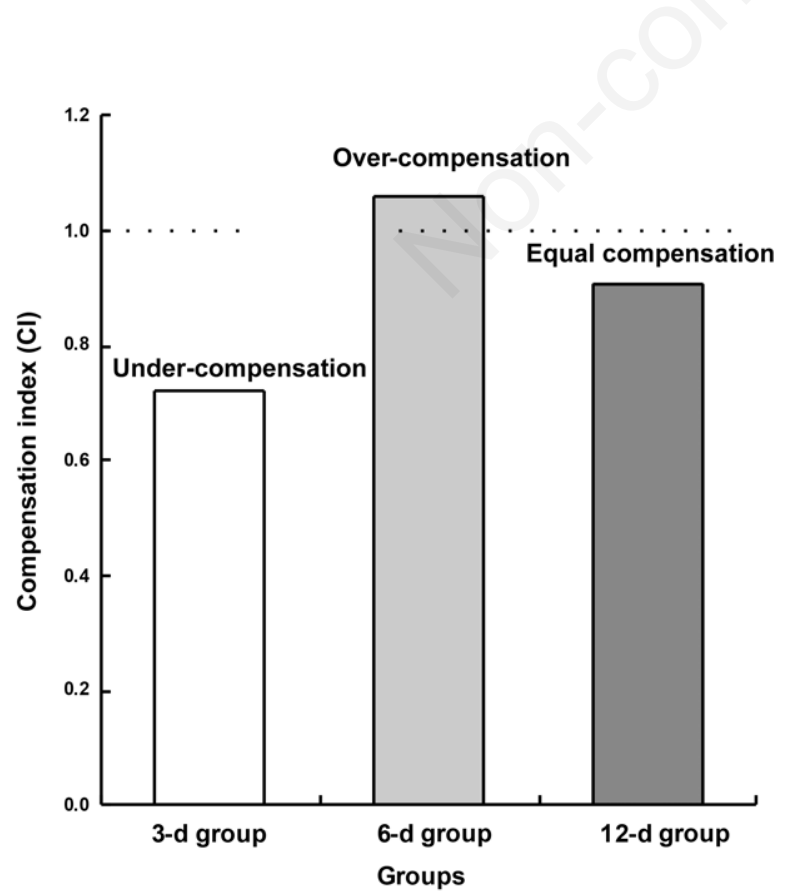

Fig. 2. Mean compensation indices (CI) of the M. aeruginosa cell density. ing the first 12 days, eventually decreasing to the same level as that of the control.

The trend observed for CAT activity is shown in Fig. $3 \mathrm{~b}$. There was an increase of CAT activity during the stress phase, with $0.390 \mathrm{U} \mathrm{mg} \mathrm{pro}^{-1}$ obtained at $12 \mathrm{~d}$, a value 7.36-fold higher than that of the control. During the recovery phase, the CAT activities in the 3-d and 12-d groups decreased significantly with the recovery time and the CAT activity in the 6-d group exhibited a dramatic increase in the first 12 recovery days and then decreased. During the entire recovery phase, the SOD activities of the 6-d group were the highest. At the end of the experiment, the four groups tended to be similar. There was also a POD activity increase during the stress phase (Fig. 3c), with $0.998 \mathrm{U} \mathrm{mg} \mathrm{pro}^{-1}$ obtained at $12 \mathrm{~d}$, a value 5.64-fold higher than that of the control. During the recovery phase, the POD activities in the 3-d, 6- $\mathrm{d}$ and 12-d groups decreased slightly. In the entire recovery phase, for POD activity, the order is as follows: 12-d group $>6-\mathrm{d}$ group $>$ 3 -d group $>$ control. At the end of the experiment, the three stress groups tended to be the same; however, the POD activities were all significantly higher than that of the control.

Taken together, the activity of SOD, CAT, and POD increased remarkably with moderate high-temperature stress. During the recovery phase, the enzyme activities decreased with time, and the difference among treatments reduced over time.

\section{MDA content of $M$. aeruginosa}

As shown in Fig. 4, during the stress phase, the MDA content was significantly enhanced by temperature stress. The MDA content increased significantly with time. During the recovery phase, the MDA content decreased significantly with the recovery time. At the end of the experiment, the MDA levels in treatments with moderate high-temperature stress were higher than that of the control. During the entire culture period, for the MDA content, the order is as follows: 12-d group $>6-\mathrm{d}$ group $>3-\mathrm{d}$ group $>$ control. The MDA of the control exhibited no significant changes during the stress phase and the recovery phase.

\section{Grey correlation analysis between $M$. aeruginosa cell density and biochemical indices during the recovery phase}

As presented in Tab. 2, if an impact factor is more important to the target factor than other impact factors, then the grey correlation grade between the impact factor and the target factor is greater than the other grey correlation grades. According to Tab. 2, the most influential sub-factor of the cell density of M. aeruginosa is Chl-a (0.7959), followed by soluble sugar (0.6851), and SOD (0.6701). 
Tab. 1. Chl-a, soluble protein content, and soluble sugar content of M. aeruginosa during the stress and recovery phase.

\begin{tabular}{|c|c|c|c|c|c|c|}
\hline \multirow[t]{2}{*}{ Index } & & \multirow[t]{2}{*}{ Time (d) } & \multicolumn{4}{|c|}{ Treatment } \\
\hline & & & 3-d group & 6-d group & 12-d group & Control \\
\hline \multirow{8}{*}{$\begin{array}{l}\text { Chl-a concentration } \\
\left(\mathrm{mg} 10^{6} \text { cells }\right)\end{array}$} & Stress phase & 0 & $0.18 \pm 0.01$ & $0.18 \pm 0.01$ & $0.18 \pm 0.01$ & $0.18 \pm 0.00$ \\
\hline & & 3 & $0.15 \pm 0.01$ & $0.15 \pm 0.01$ & $0.15 \pm 0.01$ & $0.24 \pm 0.02$ \\
\hline & & 6 & - & $0.24 \pm 0.01$ & $0.24 \pm 0.01$ & $0.33 \pm 0.01$ \\
\hline & & 12 & - & - & $0.32 \pm 0.00$ & $0.36 \pm 0.01$ \\
\hline & Recovery phase & 6 & $0.28 \pm 0.04$ & $0.31 \pm 0.02$ & $0.31 \pm 0.02$ & $0.28 \pm 0.03$ \\
\hline & & 12 & $0.26 \pm 0.02$ & $0.33 \pm 0.00$ & $0.30 \pm 0.01$ & $0.24 \pm 0.01$ \\
\hline & & 18 & $0.33 \pm 0.01$ & $0.32 \pm 0.01$ & $0.31 \pm 0.00$ & $0.33 \pm 0.01$ \\
\hline & & 30 & $0.33 \pm 0.01$ & $0.35 \pm 0.00$ & $0.35 \pm 0.00$ & $0.35 \pm 0.00$ \\
\hline \multirow{8}{*}{$\begin{array}{l}\text { Soluble protein } \\
\text { (mg } 10^{6} \text { cells) }\end{array}$} & Stress phase & 0 & $7.34 \pm 0.33$ & $7.34 \pm 0.33$ & $7.34 \pm 0.33$ & $7.34 \pm 0.33$ \\
\hline & & 3 & $7.54 \pm 0.13$ & $7.54 \pm 0.13$ & $7.54 \pm 0.13$ & $7.55 \pm 0.35$ \\
\hline & & 6 & - & $10.51 \pm 0.20$ & $10.51 \pm 0.20$ & $8.36 \pm 0.59$ \\
\hline & & 12 & - & - & $8.20 \pm 0.22$ & $7.84 \pm 1.02$ \\
\hline & Recovery phase & 6 & $10.58 \pm 1.25$ & $7.76 \pm 0.26$ & $8.60 \pm 0.89$ & $7.35 \pm 0.73$ \\
\hline & & 12 & $9.76 \pm 0.96$ & $8.12 \pm 0.58$ & $7.89 \pm 0.77$ & $6.98 \pm 0.44$ \\
\hline & & 18 & $9.14 \pm 0.55$ & $7.50 \pm 0.19$ & $6.66 \pm 0.35$ & $6.87 \pm 1.18$ \\
\hline & & 30 & $7.58 \pm 0.24$ & $8.39 \pm 0.12$ & $7.45 \pm 0.68$ & $6.99 \pm 0.13$ \\
\hline \multirow{8}{*}{$\begin{array}{l}\text { Soluble sugar } \\
\left(\mathrm{mg} 10^{6} \text { cells }\right)\end{array}$} & Stress phase & 0 & $11.29 \pm 1.46$ & $11.29 \pm 1.46$ & $11.29 \pm 1.46$ & $11.29 \pm 1.21$ \\
\hline & & 3 & $7.98 \pm 0.44$ & $7.98 \pm 0.44$ & $7.98 \pm 0.44$ & $8.22 \pm 1.02$ \\
\hline & & 6 & - & $6.91 \pm 0.30$ & $6.91 \pm 0.30$ & $9.56 \pm 0.35$ \\
\hline & & 12 & - & - & $7.22 \pm 0.24$ & $9.43 \pm 0.87$ \\
\hline & Recovery phase & 6 & $8.29 \pm 1.01$ & $9.28 \pm 0.68$ & $7.77 \pm 1.25$ & $7.81 \pm 0.33$ \\
\hline & & 12 & $6.91 \pm 0.99$ & $9.33 \pm 0.76$ & $5.83 \pm 0.11$ & $6.61 \pm 0.28$ \\
\hline & & 18 & $8.28 \pm 0.37$ & $9.03 \pm 1.49$ & $7.15 \pm 0.26$ & $7.04 \pm 0.23$ \\
\hline & & 30 & $4.45 \pm 0.22$ & $9.75 \pm 0.68$ & $11.26 \pm 0.00$ & $8.89 \pm 0.06$ \\
\hline
\end{tabular}

M. aeruginosa cultured at $25^{\circ} \mathrm{C}$ is used as the control. M. aeruginosa cultured at $35^{\circ} \mathrm{C}$ for 3,6 , and 12 days were referred to as the 3-d, 6-d, and $12-d$ groups, respectively.
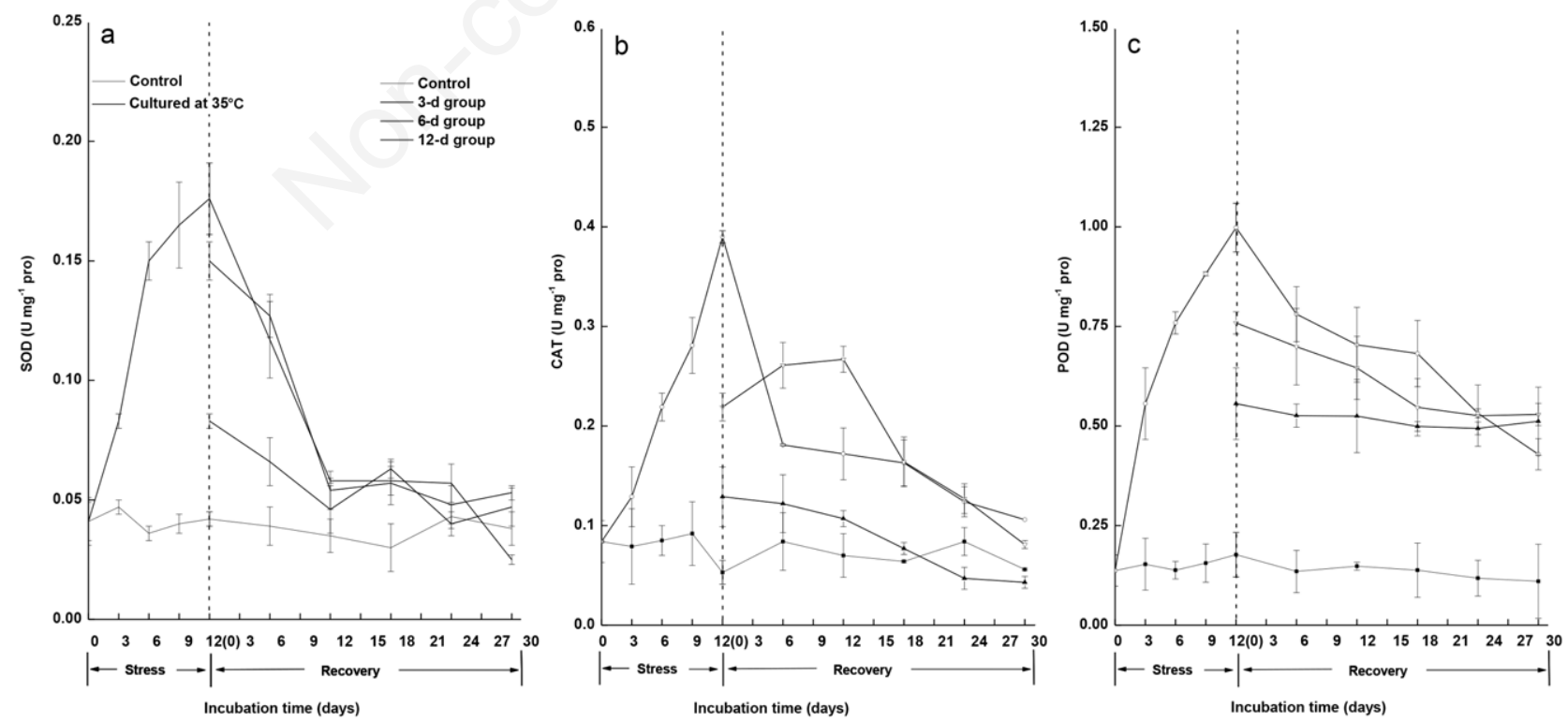

Fig. 3. Activities of SOD (a), CAT (b) and POD (c) of $M$. aeruginosa during the stress phase and the recovery phase. $M$. aeruginosa cultured at $25^{\circ} \mathrm{C}$ is used as the control. M. aeruginosa cultured at $35^{\circ} \mathrm{C}$ for 3,6 , and 12 days are referred to as the $3-\mathrm{d}$, 6 -d, and $12-\mathrm{d}$ groups, respectively. Error bars represent the standard deviations, $\mathrm{n}=3$. 


\section{Radar plot analysis}

The scores for each soil indicator are plotted in a radar plot to identify the limiting indicators (Fig. 5). The values are normalized to their maximum values. Each axis represents an indicator. The curves crossing the axes are different treatments. The lines lying at the periphery of the web have favourable values for $M$. aeruginosa growth with reference to the particular indicator (axis), and the lines toward the origin have unfavourable values.

Comparison of the indicator scores among the treatments aids in identifying the limiting parameters for a particular treatment. According to the standard, in the 3-d group, Chl-a, CAT, and soluble sugar are the limiting factors; in the 6-d group, soluble protein and MDA are the limiting factors; in the 12-d group, soluble sugar and MDA were limiting factors; in the control, almost all of the parameters were limiting factors, except MDA.

\section{DISCUSSION}

It has been reported that high temperature is one of the environmental factors that inhibit the growth of algae. In this study, during the stress phase, the growth rate under moderately high temperature was significantly lower than that of the control. However, during the recovery phase, the growth rate of the 6-d group was significantly higher than that of the control; this unexpected phenomenon was called over-compensatory growth. The result was similar to the result of Qin and Li (2010), who also observed over-compensation in M. aeruginosa after $40^{\circ} \mathrm{C}$ stress for 5 days. Although compensatory growth has been well documented in many algae (Cai et al., 2009; Flöder et al., 2010; Qin and $\mathrm{Li}, 2014)$, the biochemical mechanism of compensatory growth of $M$. aeruginosa is poorly understood.

One possibility of such compensation mechanisms is the exploitation of the change of the Chl-a content. Grey correlation analysis suggests that the most influential factor on $M$. aeruginosa cell density is Chl-a during the recovery phase. The Chl-a content has direct influence on the photosynthetic efficiency and the metabolic level, which plays a pivotal role in the plant response to temperature stress. In this study, the Chl-a concentration of $M$. aeruginosa cultured at $35^{\circ} \mathrm{C}$ was significantly lower than that at $25^{\circ} \mathrm{C}$ during the stress phase. A possible reason for this behaviour is that the accumulation of both chloroplast biogenesis and chlorophyll are also inhibited

Tab. 2. Grey correlation degree between M. aeruginosa cell density and biochemical indices during the recovery phase.

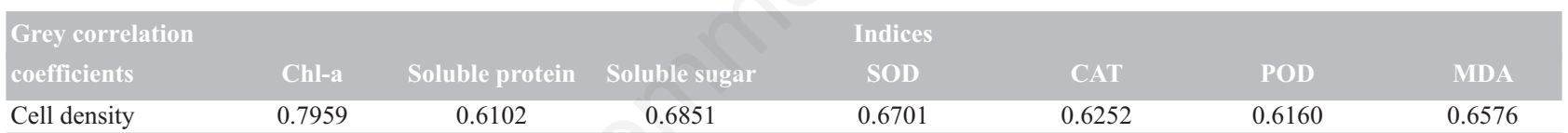

SOD, superoxide dismutase; CAT, catalase; $P O D$, peroxidase; $M D A$, malondialdehyde.

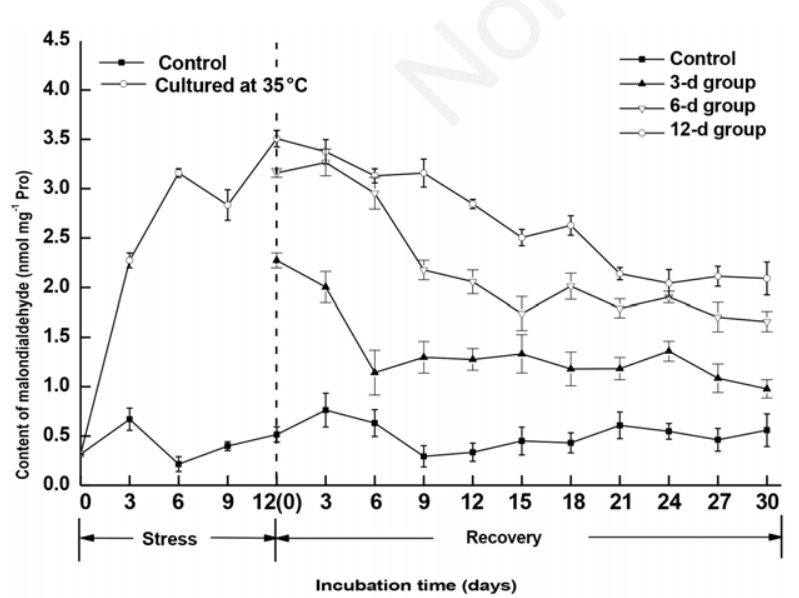

Fig. 4. MDA content of $M$. aeruginosa during the stress phase and the recovery phase. $M$. aeruginos $a$ cultured at $25^{\circ} \mathrm{C}$ is used as the control. M. aeruginosa cultured at $35^{\circ} \mathrm{C}$ for 3,6 , and 12 days are referred to as the $3-\mathrm{d}, 6-\mathrm{d}$, and 12-d groups, respectively. Error bars represent the standard deviations, $n=3$.

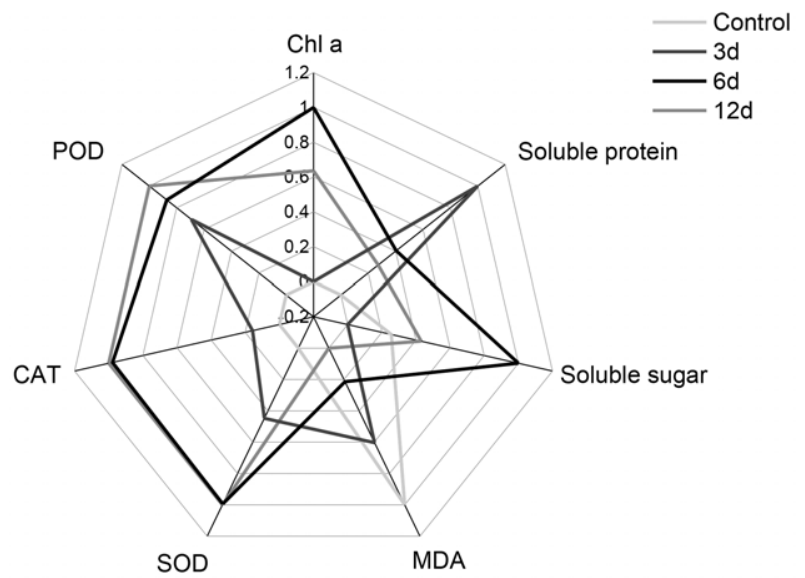

Fig. 5. Description of M. aeruginosa growth based on the 7 factors of different treatments during the recovery phase. 
at high temperatures. Interestingly, the Chl-a concentration increased during the recovery phase. This result was similar to the result of Burke, who found that a $38^{\circ} \mathrm{C}$ preincubation temperature provided maximum chlorophyll accumulation following the high temperature exposure (Burke, 2001). The increase of the chlorophyll content was seemingly controlled at the transcription level, as indicated by the changes in the expression of photosynthesis-responsive and antioxidant-related genes.

Grey correlation analysis also suggests that the soluble sugar affects the M. aeruginosa growth. Soluble sugar plays a vital role in the growth and anti-adversity of plants. It has been known for many years that organic solutes can serve as osmotic regulators in algae; the increased soluble sugar may also provide energy dissipation during the recovery phase. During the stress phase, the soluble sugar content decreased. Kirst (1981) suggested that as the temperature increases beyond the level algae can tolerate, the normal metabolic conversion would be hindered. This behaviour may occur due to the disruption of cellular structure, leading to an irreversible dissociation of macromolecules caused by the high temperature. During the recovery phase, the soluble sugar content increased compared with that of the control. Due to the increase of Chl-a during the recovery phase, there is a possibility that a great quantity of soluble sugar could have been produced by photosynthesis. We speculate that increased soluble sugar in this research may have a protective effect in M. aeruginosa to escape the moderately high temperature injury.

This $M$. aeruginosa compensatory growth is also associated with the up-regulation of soluble protein. Most proteins act as enzymes in defence or metabolic reactions, and the increased protein contents may indicate an enhanced physiological metabolism. The soluble protein of the $6^{\text {th }}$ day was the highest during the stress phase, which indicated that high temperature may induce the synthesis of more protein during the first 6 days because particular proteins would be produced under unusual environment conditions (Wahid et al., 2007). In this study, the increased protein synthesis could be a strategy for algal cells to protect and adapt themselves to high temperature. In this study, the soluble protein content decreased in 6-12 days, which may be the result of moderately high temperature causing protein damage due to excessive production of free radicals and peroxides (Zhang et al., 2007).

In response to high temperature stress, the amount of free radicals increased (Scandalios, 1993). The accumulation of free radicals may damage cellular components, leading to lipid peroxidation. The adaptation of M. aeruginosa for high temperature is also associated with up-regulation of protective enzymes because protective enzymes can defend against free radicals. Xu et al. (2006) demonstrated that the maintenance of higher antioxidant ability to mitigate lipid peroxidation and cell membrane damage is associated with heat tolerance in plants. In this study, we found that the activity of SOD, CAT, and POD rose remarkably with moderate high-temperature stress, with the activities increasing with stress time. Wang et al. (2014) also found that the SOD of wheat increased after high-temperature stress. Heat stress may induce expressive alterations in oxidative metabolism, which activates gene expression and increases antioxidative enzyme activities (Mittler et al., 2004).

Increased levels of MDA, which a product of peroxidation of unsaturated fatty acids in phospholipids, indicate oxidative damage in the algal cell membrane (Wahid et al., 2007). The produced MDA could damage membranes by increasing the membrane permeability, thus affecting the catalytic function of membrane enzymes. During the stress phase, the accumulation of MDA content in $M$. aeruginosa increased, which indicated that the membrane was continually suffering. Although the antioxidant enzyme activities increased with moderately high temperature, antioxidant enzyme activities were not sufficient to cope with the increasing amount of free radicals under the stressful conditions; as a result, the MDA increased. However, during the recovery phase, the MDA content decreased significantly with the recovery time, which indicates that after the moderately high temperature stress, the growth of M. aeruginosa returned to the normal level gradually.

Overall, M. aeruginosa developed several protective mechanisms involving increased Chl-a, soluble sugar, and protective enzyme activities to defend against moderately high temperature damage. From Fig. 5, on day 3 of the stress phase, the cell density, Chl-a content, soluble protein, and antioxidant enzyme activities of $M$. aeruginosa at $35^{\circ} \mathrm{C}$ are all different from those of the control. These factors indicate that the response to moderately high temperature occurred on the first three days. Although such changes of $M$. aeruginosa biochemical characteristics may serve as a rapid-response mechanism to help $M$. aeruginosa to cope with moderate high-temperature stress, the response level was very low, and the changes of $M$. aeruginosa were not sufficient to cope with the damage under the stressful conditions. The 3-d group has lower antioxidant enzyme activities during the recovery phase (Fig. 5). Therefore, the 3-d group exhibited undercompensation. In this experiment, the response level increased progressively during the stress phase, which means that the response level changes over time. The response level on day 6 of the stress phase was higher than that on day 3. Therefore, the 6-d group has higher antioxidant enzyme activities, higher Chl-a and soluble sugar content during the recovery phase; the 6-d group exhibited over-compensation growth. Although the 12-d group has the highest antioxidant enzyme activities during the re- 
covery phase, the level of membrane lipid peroxidation was very high, which means the damage on $M$. aeruginosa was very serious; the changes of $M$. aeruginosa occurred to cope with the serious damage of high temperature. Therefore, the 12-d group exhibited equalcompensation.

\section{CONCLUSIONS}

The growth of $M$. aeruginosa was inhibited significantly by the moderate high-temperature stress. However, after the relief of stress, the 3-d, 6-d, and 12-d groups exhibited under-compensation, over-compensation, and equal-compensation, respectively. These results indicated an effective defence system against moderately high temperature occurred on day 6 . To cope with moderate hightemperature stress, M. aeruginosa implement various mechanisms, including the scavenging of free radicals by increase antioxidant enzyme activities to maintain membrane stability, the increase of the Chl-a content, and the accumulation and adjustment of compatible solutes, such as soluble protein and sugar. The results revealed that the increase of Chl-a, soluble sugar, and SOD activity in algae cells play key roles in the compensatory growth of $M$. aeruginosa.

Although, sudden shifts of temperature are rare in natural conditions, temperature fluctuations between day and night can be great (Lauritsen and Rogers, 2012; Zhou et al., 2014). In the day time during summer, surface water temperatures can reach $35^{\circ} \mathrm{C}$ in Southern China, Southeastern North America, Middle East and other sub-tropical areas (meteorological data available from LTER Network Data Portal, https://portal.lternet.edu/nis/mapbrowse? packageid=knb-lter-ntl.10001.3). Under such conditions, temperature fluctuation in summer may trigger the M. aeruginosa defence system and cause compensatory growth of $M$. aeruginosa. This may explain the phenomenon of algal blooms frequently appearing at high temperatures.

Further studies are necessary to determine the cell density changes with the different temperature, stress time, and recovery time so that a mathematical model can be formulated to predict cyanobacteria bloom in summer.

\section{ACKNOWLEDGMENTS}

This work was supported by the Jiangsu Key Laboratory of Agricultural Meteorology (JKLAM201205), the Natural Science Fund for Colleges and Universities in Jiangsu Province (14KJB170013), the Support Program of Science and Technology in Jiangsu Province (BE2011840), and the Open Foundation of the State Key Laboratory of Soil and Sustainable Agriculture (Y212000016).

\section{REFERENCES}

Ali M, Nicieza A, Wootton RJ, 2003. Compensatory growth in fishes: a response to growth depression. Fish Fish. 4:147-190.

Barinova S, Chekryzheva T, 2014. Phytoplankton dynamic and bioindication in the Kondopoga bay, lake Onego (Northern Russia). J. Limnol. 73:282-297.

Belsky AJ, 1986. Does herbivory benefit plants? A review of the evidence. Am. Nat. 127:870-892.

Bjorndal KA, Bolten AB, Dellinger T, Delgado C, Martins HR, 2003. Compensatory growth in oceanic loggerhead sea turtles: response to a stochastic environment. Ecology 84:1237-1249.

Bradford MM, 1976. A rapid and sensitive method for the quantitation of microgram quantities of protein utilizing the principle of protein-dye binding. Anal. Biochem. 72:248-254.

Burke JJ, 2001. Identification of genetic diversity and mutations in higher plant acquired thermotolerance. Physiol. Plantarum. 112:167-170.

Cai Z, Duan S, Wei W, 2009. Darkness and UV radiation provoked compensatory growth in marine phytoplankton Phaeodactylum tricornutum (Bacillariophyceae). Aquac. Res. 40:1559-1562.

Cai Y, Kong F, 2013. Diversity and dynamics of picocyanobacteria and the bloom-forming cyanobacteria in a large shallow eutrophic lake (lake Chaohu, China). J. Limnol. 72:473-484.

Carvalho L, Mcdonald C, Hoyos C, Mischke U, Phillips G, Borics G, Poikane S, Skjelbred B, Solheim AL, Wichelen J, 2013. Sustaining recreational quality of European lakes: minimizing the health risks from algal blooms through phosphorus control. J. Appl. Ecol. 50:315-323.

Carvalho L, Miller CA, Scott EM, Codd GA, Davies PS, Tyler AN, 2011. Cyanobacterial blooms: statistical models describing risk factors for national-scale lake assessment and lake management. Sci. Total. Environ. 409:5353-5358.

Chance B, Maehly AC, 1955. Assay of catalases and peroxidases. Method. Enzymol. 2:764-775.

Chen M, Li J, Dai X, Sun Y, Chen F, 2011. Effect of phosphorus and temperature on chlorophyll a contents and cell sizes of Scenedesmus obliquus and Microcystis aeruginosa. Limnology 12:187-192.

Deng JL, 1989. Introduction to grey system theory. J. Grey System. 1:1-24.

Erbilgin N, Galvez DA, Zhang B, Najar A, 2014. Resource availability and repeated defoliation mediate compensatory growth in trembling aspen (Populus tremuloides) seedlings. PeerJ 2:e491.

Fang J, Tian X, Dong S, Fang J, Zhang J, 2014. An experimental study on the compensatory growth of tongue sole, Cynoglossus semilaevis (Günther, 1873), following lower temperature manipulation. Aquac. Res. 45:1523-1532.

Flöder S, Jaschinski S, Wells G, Burns CW, 2010. Dominance and compensatory growth in phytoplankton communities under salinity stress. J. Exp. Mar. Biol. Ecol. 395:223-231.

Gong XY, Fanselow N, Dittert K, Taube F, Lin S, 2015. Response of primary production and biomass allocation to nitrogen and water supplementation along a grazing intensity gradient in semiarid grassland. Eur. J. Agron. 63:27-35.

Gu H, Lu L, Yuan Q, Zhao J, Han R, Zhou Y, 2006. A comparison between two methods for determination of SOD activity. Chin. Pharm. Biotechnol. 13:377-379. 
Heath RL, Packer L, 1968. Photoperoxidation in isolated chloroplasts: I. Kinetics and stoichiometry of fatty acid peroxidation. Arch. Biochem. Biophys. 125:189-198.

Huang XF, Chen WM, Cai QM. 1999. [Survey, observation and analysis of lake ecology], p. 72-79. In: [Standard methods for observation and analysis in Chinese Ecosystem Research Network].[Book in Chinese]. Standards Press of China, Beijing.

Isaacs JD, Strangman WK, Barbera AE, Mallin MA, Mciver MR, Wright JLC, 2014. Microcystins and two new micropeptin cyanopeptides produced by unprecedented Microcystis aeruginosa blooms in North Carolina's Cape Fear River. Harmful Algae 31:82-86.

Jacoby JM, Collier DC, Welch EB, Hardy FJ, Crayton M, 2000. Environmental factors associated with a toxic bloom of $\mathrm{Mi}$ crocystis aeruginosa. Can. J. Fish. Aquat. Sci. 57:231-240.

Joehnk KD, Huisman JEF, Sharples J, Sommeijer B, Visser PM, Stroom JM, 2008. Summer heatwaves promote blooms of harmful cyanobacteria. Global. Change. Biol. 14:495-512.

Kirst GO, 1981. Osmotic adaptation in algae, p. 180 (abstract). Proceedings 13th Int. Bot. Congr., Sidney, Australia.

Kochert G, 1978. Carbohydrate determination by the phenolsulfuric acid method. Handbook of phycological methods 2:95-97.

Lauritsen RG, Rogers JC, 2012. US diurnal temperature range variability and regional causal mechanisms, 1901-2002. J. Climate 25:7216-7231.

Laxman RH, Rao NKS, Biradar G, Sunoj VSJ, Shivashankara KS, Pavithra CB, Dhanyalakshmi KH, Manasa KM, Bhatt RM, Sadashiva AT, 2014. Antioxidant enzymes activity and physiological response of tomato (Lycopersicon esculentum M.) genotypes under mild temperature stress. J. Plant Physiol. 19:161-164.

Lehman PW, Marr K, Boyer GL, Acuna S, Teh SJ, 2013. Longterm trends and causal factors associated with Microcystis abundance and toxicity in San Francisco Estuary and implications for climate change impacts. Hydrobiologia 718:141-158.

Liu X, Lu X, Chen Y, 2011. The effects of temperature and nutrient ratios on Microcystis blooms in Lake Taihu, China: an 11-year investigation. Harmful Algae 10:337-343.

Mangel M, Munch SB, 2005. A life-history perspective on shortand long-term consequences of compensatory growth. Am. Nat. 166:E155-E176.

Mittler R, Vanderauwera S, Gollery M, Van Breusegem F, 2004. Reactive oxygen gene network of plants. Trends Plant Sci. 9:490-498.

Nikki J, Pirhonen J, Jobling M, Karjalainen J, 2004. Compensatory growth in juvenile rainbow trout, Oncorhynchus mykiss (Walbaum), held individually. Aquaculture 235:285-296.

O’Neil JM, Davis TW, Burford MA, Gobler CJ, 2012. The rise of harmful cyanobacteria blooms: the potential roles of eutrophication and climate change. Harmful Algae 14:313-334.

Qin H, Li D, 2010. [Over-compensatory growth of Microcystis aeruginosa after high temperature stress].[Article in Chinese]. Environ. Sci. 31:1504-1509.

Qin H, Li D, 2014. Enhanced resistance to UV-B radiation in Anabaena sp. PCC 7120 (Cyanophyceae) by repeated exposure. Curr. Microbiol. 69:1-9.

Rao MV, Paliyath G, Ormrod DP, 1996. Ultraviolet-B-and ozone-induced biochemical changes in antioxidant enzymes of Arabidopsis thaliana. Plant Physiol. 110:125-136.
Remen M, Aas TS, Vågseth T, Torgersen T, Olsen RE, Imsland A, Oppedal F, 2014. Production performance of Atlantic salmon (Salmo salar L.) postsmolts in cyclic hypoxia, and following compensatory growth. Aquac. Res. 45:1355-1366.

Rippka R, Deruelles J, Waterbury JB, Herdman M, Stanier RY, 1979. Generic assignments, strain histories and properties of pure cultures of cyanobacteria. J. Gen. Microbiol. 111:1-61.

Robarts RD, Zohary T, 1987. Temperature effects on photosynthetic capacity, respiration, and growth rates of bloom-forming cyanobacteria. New Zeal. J. Mar. Fresh. 21:391-399.

Robert CAM, Ferrieri RA, Schirmer S, Babst BA, Schueller MJ, Machado RAR, Arce C, Hibbard BE, Gershenzon J, Turlings TCJ, 2014. Induced carbon reallocation and compensatory growth as root herbivore tolerance mechanisms. Plant Cell Environ. 37:2613-2622.

Scandalios JG, 1993. Oxygen stress and superoxide dismutases. Plant Physiol. 101:7.

Stocker TF, Qin D, Plattner GK, Tignor M, Allen SK, Boschung J, Nauels A, Xia Y, Bex B, Midgley BM, 2013. IPCC, 2013: Climate change 2013: the physical science basis. Contribution of working group I to the fifth assessment report of the intergovernmental panel on climate change.

Sun D, Li Y, Wang Q, Le C, Lv H, Huang C, Gong S, 2012. A novel support vector regression model to estimate the phycocyanin concentration in turbid inland waters from hyperspectral reflectance. Hydrobiologia 680:199-217.

Tang Q, Feng M. 2006. DPS data Processing system: experimental design, statistical analysis and modeling, p. 604. Beijing: Science Press (in Chinese).

Tikhomirova EV, 1985. Changes of nitrogen metabolism in millet at elevated temperatures. Field. Crop. Res. 11:259-264.

Turley NE, Godfrey RM, Johnson MTJ, 2013. Evolution of mixed strategies of plant defense against herbivores. New Phytol. 197:359-361.

Van Gremberghe I, Leliaert F, Mergeay J, Vanormelingen P, Van Der Gucht K, Debeer AE, Lacerot G, De Meester L, Vyverman W, 2011. Lack of phylogeographic structure in the freshwater cyanobacterium Microcystis aeruginosa suggests global dispersal. PloS one 6:e19561.

Wahid A, Close TJ, 2007. Expression of dehydrins under heat stress and their relationship with water relations of sugarcane leaves. Biol. Plantarum 51:104-109.

Wahid A, Gelani S, Ashraf M, Foolad MR, 2007. Heat tolerance in plants: an overview. Environ. Exp. Bot. 61:199-223.

Wang C, Wen D, Sun A, Han X, Zhang J, Wang Z, Yin Y, 2014. Differential activity and expression of antioxidant enzymes and alteration in osmolyte accumulation under high temperature stress in wheat seedlings. J. Cereal Sci. 60:653-659.

Xu S, Li J, Zhang X, Wei H, Cui L, 2006. Effects of heat acclimation pretreatment on changes of membrane lipid peroxidation, antioxidant metabolites, and ultrastructure of chloroplasts in two cool-season turfgrass species under heat stress. Environ. Exp. Bot. 56:274-285.

Yang Z, Geng L, Wang W, Zhang J, 2012. Combined effects of temperature, light intensity, and nitrogen concentration on the growth and polysaccharide content of Microcystis aeruginosa in batch culture. Biochem. Syst. Ecol. 41: 130-135.

Ye L, Shi X, Wu X, Kong F, 2012. Nitrate limitation and accumulation of dissolved organic carbon during a spring-sum- 
mer cyanobacterial bloom in Lake Taihu (China). J. Limnol. 71:67-71.

Yu X, Zhou J, Wang Z, Cai W, 2010. Preparation of visible lightresponsive $\mathrm{AgBiO}_{3}$ bactericide and its control effect on the $\mathrm{Mi}$ crocystis aeruginosa. J. Photoch. Photobiolo. B 101:265-270.

Yuan BZ, Wang J, Zhao SL, Sun J, 1998. An approach to the mechanism of plant compensation. Chin. J. Ecol. 17:45-49 (in Chinese).

Zehnder A, Gorham PR, 1960. Factors influencing the growth of Microcystis aeruginosa Kütz. Emend. Elenkin. Can. J. Microbiol. 6:645-660.
Zhang FQ, Wang YS, Lou ZP, Dong JD, 2007. Effect of heavy metal stress on antioxidative enzymes and lipid peroxidation in leaves and roots of two mangrove plant seedlings (Kandelia candel and Bruguiera gymnorrhiza). Chemosphere 67:44-50.

Zhang P, Zhai C, Chen R, Liu C, Xue Y, Jiang J, 2012. The dynamics of the water bloom-forming Microcystis aeruginosa and its relationship with biotic and abiotic factors in Lake Taihu, China. Ecol. Eng. 47:274-277.

Zhou X, Zhao A, Meng X, Chen R, Kuang X, Duan X, Kan H, 2014. Acute effects of diurnal temperature range on mortality in 8 Chinese cities. Sci. Total. Environ. 493:92-97. 